\title{
Pulmonary echinococcosis mimicking Pancoast tumor
}

\author{
Yekta Altemur Karamustafaoglu, MD, Yener Yoruk, MD, Rustem Mamedov, MD, and \\ Ilkay Yavasman, MD, Edirne, Turkey
}

Hydatid cyst disease is caused by the larval form of Echinococcus granulosus, and this parasitic infestation is an important health problem in endemic areas (Turkey, Middle Eastern countries, and South America). The lung and the liver are the most common sites of hydatidosis, but the parasite can be found in any part of the body except hair, teeth, and fingernails. Pulmonary hydatid cyst is sometimes mistaken for other pathologic processes according to location. We report the case of a surgically treated pulmonary hydatid cyst that clinically and radiologically mimicked Pancoast tumor.

\section{CLINICAL SUMMARY}

A 44-year-old man was admitted with right arm and shoulder pain and right arm paresthesia. There was no atrophy of hand and arm muscles and no Horner syndrome. Chest radiography showed a mass in the right apical region of the thorax. Thoracic computed tomography (CT) revealed a soft-tissue density in the posterior right upper lobe with complete destruction of the proximal part of the posterior localization of the second rib together with erosive changes of the third rib (Figure 1). The lesion was interpreted as extrathoracic tumor expansion. Maximum standard uptake value of the mass was measured at 4.26 by positron emission tomography, and the lesion was reported as Pancoast tumor with second rib invasion. Magnetic resonance imaging showed multiple cystic lesions between paraspinal muscles, with destructive changes in the transverse process, the body of the second thoracic vertebra, and part of the posterior second and third ribs (Figure 2). Routine laboratory and peripheral blood test results were within reference ranges; serologic testing was not done.

Right Paulson thoracotomy was applied, with a preoperative diagnosis of complicated hydatid cyst in light of the magnetic resonance imaging. At the thoracotomy, multiple cysts were found to be contained by the germinative membrane, with posterior chest wall invasion into the paraspinal muscles and partial destruction of the second and third ribs and second vertebral body. The spinal canal was intact. All

\footnotetext{
From the Department of Thoracic Surgery, Faculty of Medicine, Trakya University, Edirne, Turkey.

Received for publication Sept 19, 2008; accepted for publication Nov 3, 2008; available ahead of print April 3, 2009.

Address for reprints: Yekta Altemur Karamustafaoglu, MD, Trakya University, Faculty of Medicine, Department of Thoracic Surgery, Kat:4 22030 Edirne, Turkey (E-mail: altemurk@hotmail.com).

J Thorac Cardiovasc Surg 2010;139:e57-8 0022-5223/\$36.00

Copyright (c) 2010 Published by Elsevier Inc. on behalf of The American Association for Thoracic Surgery

doi:10.1016/j.jtcvs.2008.11.018
}

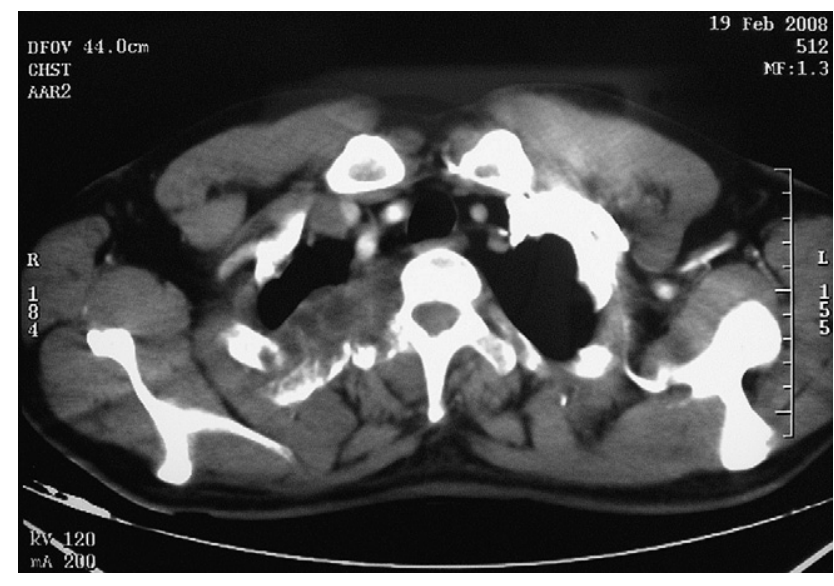

FIGURE 1. Computed tomography shows right upper zone tumor with second and third rib invasion.

cysts were extrapulmonary with intact parietal pleura. Partial resections of the second and third ribs were performed, and spinal stabilization was not needed. The multiple cysts were removed by suction from pleura between paraspinal muscles. The surgical field was preserved with povidone-iodine gauzes to prevent pleural dissemination. Histopathologic examination confirmed hydatid cyst. The postoperative course was uneventful, with albendazole (INN albendazolum) at $800 \mathrm{mg} / \mathrm{d}$ administered for 3 months.

\section{DISCUSSION}

This case represents a rare and infrequently reported presentation of hydatid disease. ${ }^{1}$ A wide diversity of other conditions can result in Pancoast syndrome, including primary bronchogenic carcinoma, other primary thoracic neoplasms, metastatic neoplasms, hematologic neoplasms, and infectious processes (hydatid cyst). The hydatid mass is usually cystic and sometimes causes destructive changes to adjacent organs and bone tissue. ${ }^{2}$ Chest radiography and CT are the main diagnostic tools to detect intrathoracic hydatid cyst. CT is helpful in showing the water density of intact cysts, but complicated cysts may be confused with mass lesions. Coronal and sagittal magnetic resonance imaging is a more useful diagnostic tool than CT for extension of primary bony and vertebral hydatid cyst, as well as Pancoast tumor invasion through the superior sulcus. ${ }^{3}$ In soft tissues, the cyst typically contains multiple vesicles in the mother cyst as a result of endogenous proliferation of the germinal layer. ${ }^{4}$ In the operation, we extirpated multiple cysts, but there was no chitinous membrane because the cysts were not surrounded by lung tissue. Although serologic tests are widely used to 


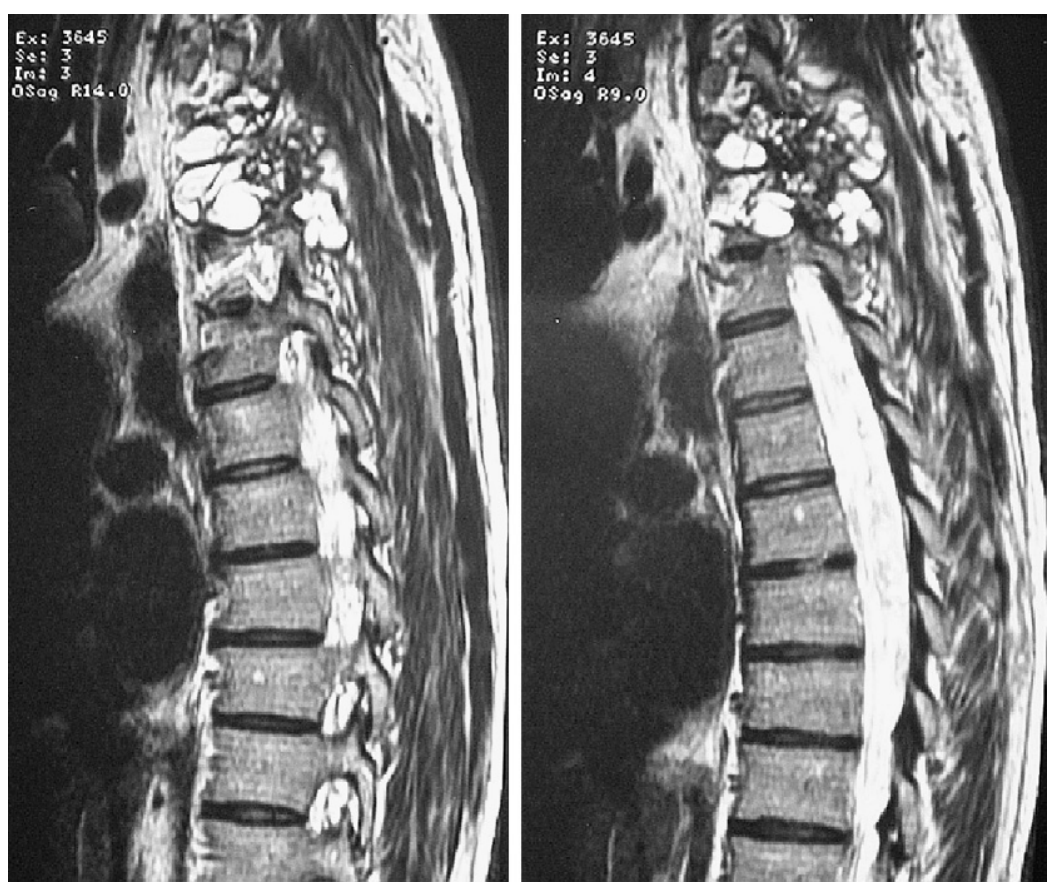

FIGURE 2. Magnetic resonance imaging shows multiple cystic image with second and third thoracic vertebral body involvement.

confirm the diagnosis of hydatid cyst, these tests may have false-negative or -positive results. Positive serologic results thus do not definitively confirm the diagnosis, nor do negative serologic results absolutely exclude the disease. ${ }^{4}$ The effective treatment of lung and vertebral cysts is complete excision of the cysts without delay, with maximum preservation of the lung parenchyma. While the cyst is being extirpated, the surgeon must be careful to avoid disrupting the cyst. We do not give albendazole before surgery; however, postoperative albendazole treatment should be given to patients at high risk for recurrence (those with multiple hydatid cysts in the thoracic cavity, multiple organ cysts, or ruptured hydatid cyst).
Hydatid cyst is both an operable and prognostically favorable lesion. In endemic areas, it must be considered in the differential diagnosis of Pancoast syndrome.

\section{References}

1. Aghajanzadeh M, Molaie R, Aghajanzadeh H, Marandi KF. Hydatid cyst as a cause of Pancoast's syndrome. Arch Iran Med [serial online]. 1999;2(1). Available at: http://www.ams.ac.ir/AIM/9812/aghajanzadeh9812.html.

2. Gencer M, Ceylan E. Pulmonary echinococcosis with multiple nodules mimicking metastatic lung tumor in chest radiography. Respiration. 2008;75:345.

3. National Collaborating Centre for Acute Care. The diagnosis and treatment of lung cancer. London: National Institute for Clinical Excellence; 2005. p. 32.

4. Atalay F, Orug T, Arda K, Tosun O, Atalay F. An unusual case of hydatid disease located in the erector spinae muscle. JBR-BTR. 2003;86:329-331. 